\title{
The Scientific Proceedings of "Leishmaniasis: The First Centenary 1885-1985" Held at The Royal Army Medical College, 9th November, 1985
}

\author{
Edited by Dr D T Hart,
}

International Institute for Cellular and Molecular Pathology, Tropical Disease Research Unit, Avenue Hippocrate 74.39, B-1200

Brussels, Belgium

\author{
Historical Perspectives \\ Brigadier N W J England \\ Ministry of Defence \\ First Avenue House \\ High Holborn \\ London WC1V 6HE
}

\section{Introduction}

The man whose name we are honouring today, Colonel D D Cunningham, was born in 1843 and educated at Edinburgh University were he graduated with honours in medicine in 1867 . He entered the Indian Medical Service, and during his attendance on the Tropical Diseases Course at the Army Medical School (then located at Netley), his potential as a research scientist was recognised and he was sent to Germany in company with Dr T R Lewis of the Army Medical Department to master special techniques and to work for a time under Pettenkofer in Munich. On return to England, the 2 officers at once left for India and on arrival in Calcutta in January 1869 , were attached as special assistants to the department of the Sanitary Commissioner. For the next 10 years they collaborated in important pathological and hygiene studies and the more important of their results were published after Lewis's death in 1888 in a memorial volume, "Physiological and Pathological Researches". Afterwards Cunningham held, for many years, the post of Professor of Physiology in the Calcutta Medical College. His considerable academic achievements in applied pathology studies which formed the basis for sanitary administration, were recognised by him being made a Companion of the Order of the Indian Empire in 1893 and being elected a Fellow of the Royal Society in 1889 . He was promoted to full Colonel on the retired list on appointment as Honorary Physician to the King, and died in 1914.

\section{Cutaneous Leishmaniasis}

Cunningham (1885) published an article in the Scientific Memoirs by Medical Officers of the Army of India, "On the Presence of Peculiar Parasitic Organisms in the Tissue of a Specimen of Delhi Boil". He gave a masterly description of the histological feature of cutaneous leishmaniasis and, in addition, identified numerous round and oval intracellular bodies which only stained with gentian violet alone or combined with fuchsin. He noted that these structures were distributed throughout the lesion but were more numerous where the pathological process was most intense.

$\mathrm{He}$ eventually concluded that the organisms represented various stages of an organism of the mycetozoic nature, probably Monadinae, showing zoocysts and sporocysts. Whatever their exact nature, he was confident that these bodies were associated with, and probably caused, the disease. From his superb line drawings of these structures, it is clear that he had visualised clusters of amastigotes of Leishmania i macrophages, together with other structures such ds 윽 mast-cells, trichohyaline bodies and cellular debriso When it is remembered that he was handicapped bo enormous technical difficulties caused by hardening ang shrinkage of tissue fixed in absolute alcohol and inferion stains available at that time, it was a remarkabe achievement and well deserving its commemoratiog paid by this Centenary Symposium.

Little attention was paid to these observations, but i⿱ 1891, Firth described the organism and gave the name Sporozoa furunculosa. Although, as pointed out by Hoare in 1938, it was accurately described in 1898 by

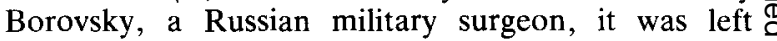
to Wright, in Boston, using a greatly improved $\overrightarrow{\overrightarrow{0}}$ Romanowsky stain, to give a complete description $\frac{3}{3}$ obtained from a tropical ulcer in a patient from $\vec{F}$ Armenia. He gave them the name Helcosoma tropica, later changed by Lühe, in 1906, to Leishmania tropica.

\section{Visceral Leishmaniasis}

In the same way as Wright's improved stain facilitated detailed visualisation of the minute structure of the Protozoa, so Leishman's improved stain, developed at the Royal Army Medical College, Netley and published $\frac{5}{3}$ in 1901, enabled him to identify organisms in splenic smears from a patient who had died from Dum-dum $ᄋ$ fever. He described oval organisms of up to $5 \mu$ in length

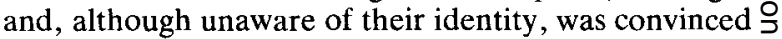
that they were Protozoa. Two years later, while $\rightarrow$ experimenting on trypanosomiasis, he found similar bodies in the blood of an infected rat which had been $N$ dead for 2 days. He proposed that the bodies seen in the Dum-dum fever patient were in fact degenerate 0 
trypanosomes. His findings were published in the British Medical Journal on 30 May 1903 in a paper, "On the Possibility of the Occurrence of Trypanosomiasis in India". A few months later a letter appeared in the same journal from Captain C. Donovan in Madras, stating that in April and June 1903 he had found similar bodies in splenic smears from patients with prolonged fever. This ruled out Leishman's theory that the parasites were degenerating trypanosomes and, also at that time, Wright reported similar findings from a tropical ulcer. Major Ronald Ross, then Professor of Tropical Medicine in Liverpool, having seen Donovan's material, voiced the opinion that the cases were suggestive of kalaazar. He did not accept that the bodies were trypanosomes and suggested they were Sporozoa and proposed the name Leishmania donovani.

Leonard Rogers, in Assam, made splenic smears from patients with kala-azar and published these results in the Indian Medical Gazette (1904). Unfortunately, he was forestalled by Ross who, in collaboration with a colleague in India, Dr C Bentley, made similar observations which were reported in the British Medical Journal a few months earlier. Rogers, having recognised the importance of Leishman's suggestion of the possibility of the association between cercomonads in tropical sore and Leishmania parasites, attempted to culture the organisms. Eventually he was successful and demonstrated that the small oval bodies elongated and developed flagella. This clearly showed their relationship to trypanosomes and excluded the sporozoal nature of their origin.

These findings were not immediately accepted, and it was not until Leishman investigated another patient with Dum-dum fever at Netley in 1904 and confirmed Roger's findings on culture, that he finally established that the parasite belonged to the trypanosome family.

Many years later, Sinton, Napier and others postulated that Phlebotomus was the vector of Indian kala-azar, but it was not until 1942 that Shortt and colleagues proved this experimentally.

A vast amount of research into all aspects of leishmaniasis has taken place in the 100 years following Cunningham's discovery, but there are still mysteries to be unravelled and some of these are described in the subsequent papers of this symposium.

\section{Acknowledgements}

The Leishman Centenary Oration by Sir John Boyd (1966) J R Army Med Corps; 112; 4.

\section{REFERENCES}

BOROVSKY P F. (1909) Voenno-Medicinskij Zh; 195 : 925. CunNingham D D. (1885) Scient Mem med Offrs Army India; 1: 21 .

Donovan C. (1903) Br med J; ii: 1401.

HoARE C A. (1938) Trans R Soc Trop Med Hyg; 32: 67-92. LEISHMAN W B. (1901) Br med $J$; ii: 757.

LEISHMAN W B. (1903) Br med $J$; i: 1252

Leishman W B and STATHAm (1904) J R Army Med Corps; 927.

ROGERS L. (1904) Indian med Gaz; 39: 158.

Ross R. (1903) Br med J; ii: 140.

Ross R (1904) Br med J; i: 160.

SWAMINATH C S, ShORTt H E and ANDERSON L A P. (1942 Indian J med Res; 30: 473.

WRIGHT J M. (1903) J med Res; 10: 472-482. 